\title{
A CONSTRUÇÃO DO SUJEITO NA PERSPECTIVA DE JEAN-PAUL SARTRE
}

\author{
The Construction of the Subject in the Perspective of Jean-Paul Sartre
}

La Construcción del Sujeto en la Perspectiva de Jean-Paul Sartre

\section{La Construction du Sujet dans la Perspective de Jean-Paul Sartre}

Cezar Augusto Vieira Junior

Mestrando em Psicologia pela Universidade Federal de Santa Maria. Bolsista CAPES. Integrante do Grupo de Pesquisa "Saúde, Minorias Sociais e Comunicação" da Universidade Federal de Santa Maria - UFSM.

Hector Omar Ardans-Bonifacino

Doutor em Psicologia (Psicologia Social) pela Pontifícia Universidade Católica de São Paulo. Pós-doutor em Psicologia Social pela Universidade de São Paulo. Livre-docente em Psicologia Socioambiental pela Universidade de São Paulo. Professor no Curso de Psicologia da Universidade Federal de Santa Maria - UFSM.

Adriane Roso

Doutora em Psicologia pela Pontifícia Universidade Católica do Rio Grande do Sul, com período sanduíche na Columbia University. Pós-Doutora em Comunicação pela Universidade Federal de Santa Maria - UFSM. Bolsista de Produtividade em Pesquisa do CNPq. Professora do Programa de PósGraduação em Psicologia da UFSM.

Recebido em: 25/02/2016 / Revisado em: 18/04/2016 / Aceito em: 26/04/2016

\section{Resumo}

Este ensaio tem o objetivo de elucidar como se dá o processo de construção do sujeito, a partir da abordagem existencialista de Jean-Paul Sartre, de forma a contribuir para algumas aproximações entre o existencialismo sartriano e a psicologia social. Na busca de alcançar esse objetivo, realizamos um estudo utilizando as principais obras do pensador francês, bem como de outros autores que estudam o existencialismo. Nesse sentido, desenvolvemos este ensaio filosófico em três partes, as quais perfazem uma trajetória sobre o pensamento do autor, buscando destacar conceitos importantes para a compreensão de suas ideias. A primeira delas aborda pontos mais básicos do pensamento sartriano, como a consciência e os aspectos do ser. Em seguida, delineamos temas fundamentais de sua filosofia, tais como liberdade, campo dos possíveis e má-fé. Por fim, concentramos a discussão nas relações e processos que culminam na construção do sujeito. Com este percurso, visamos evidenciar as importantes contribuições que o pensamento existencialista sartriano pode oferecer ao campo de atuação da psicologia social.

Palavras-chave: psicologia social; existencialismo; Sartre; sujeito; liberdade.

\section{Abstract}

This essay aims to elucidate how the process of construction of the subject takes place, starting from the existentialist approach of JeanPaul Sartre, in order to contribute to some approximations between Sartrian existentialism and social psychology. In the search to achieve this goal, we conducted a study using the main works of the French thinker, as well as other authors who study existentialism. In this sense, we develop this philosophical essay in three parts, which form a trajectory on the author's thought, seeking to highlight important concepts for the understanding of his ideas. The first of them addresses more basic points of Sartre's thinking, such as consciousness and aspects of being. Then we outline fundamental themes of his philosophy, such as freedom, the field of possible and bad faith. Finally, we focus the discussion on the relationships and processes that culminate in the construction of the subject. With this course, we aim to 
highlight the important contributions that Sartre's existentialist thought can offer to the social psychology field.

Keywords: Social Psychology; existentialism; Sartre; subject; freedom.

\section{Resumen}

Este ensayo tiene el objetivo de aclarar como ocurre el proceso de construcción del sujeto desde el enfoque existencialista de Jean-Paul Sartre, de modo a contribuir para algunas aproximaciones entre el existencialismo sartriano y la psicología social. En la búsqueda por alcanzar estos objetivos, realizamos un estudio utilizando las principales obras del pensador francés, así como de otros autores que estudian el existencialismo. En este sentido, desarrollamos este ensayo filosófico en tres partes, las cuales se hace una trayectoria acerca del pensamiento del autor, buscando enfocar conceptos importantes para La comprensión de sus ideas. La primera de ellas trae puntos más básicos del pensamiento sartriano, como la consciencia y el aspecto del ser. En seguida, delineamos temas fundamentales de su filosofía, tales como libertad, campo de los posibles y mala fe. Por fin, concentramos la discusión en las relaciones y procesos que terminan la construcción del sujeto. Con este recorrido, queremos evidenciar las importantes contribuciones que el pensamiento existencialista sartriano puede ofrecer al campo de actuación de la psicología social.

Palabras clave: psicología social; existencialismo; Sartre; sujeto; libertad.

\section{Résumé}

Cet essai vise à élucider comment se passe le processus de construction du sujet, à partir de l'approche existentielle de Jean-Paul Sartre, de façon à contribuer à certains rapports entre l'existentialisme de sartre et la psychologie sociale. Pour atteindre cet objectif, nous avons mené une étude en utilisant les ouvres majeures du penseur français, ainsi que d'autres auteurs qui étudient l'existentialisme. À cette fin, nous avons développé cet essai philosophique en trois parties qui forment une trajectoire sur la pensée de l'auteur, en mettant en évidence des notions importantes pour la compréhension de ses idées. La première partie éxamine les points plus fondamentaux de la pensée de Sartre, comme la conscience et les aspects de l'être. Ensuite, nous avons décrit les thèmes fondamentaux de sa philosophie, comme la liberté, le champ du possible et la mauvaise foi. Enfin, nous avons centré le débat sur les relations et les processus qui aboutissent à la construction du sujet. Avec ce parcours, notre objectif est de souligner les importantes contributions que la pensée existentialiste de Sartre peut offrir dans le domaine de la psychologie sociale.

Mots-clés: psychologie sociale; existentialisme; Sartre; sujet; liberté.

O presente ensaio explora o processo de construção do sujeito a partir da abordagem existencialista proposta por JeanPaul Sartre (1905-1980)1 . O conhecimento produzido a partir de suas obras filosóficas culminou nas três grandes biografias que desenvolveu (Charles Baudelaire, Jean Genet e Gustave Flaubert), buscando através delas aplicar suas proposições para a compreensão do sujeito histórico-dialético, que muito tem a contribuir com a psicologia. Schneider (2011, p. 21) argumenta que essas obras biográficas expressam “o conjunto das concepções teórico-metodológicas do existencialista e demonstram a viabilidade de seu método e de sua psicologia".

A análise desenvolvida por Sartre nas biografias expande nosso olhar sobre a compreensão do sujeito, diferente dos pressupostos já instituídos por psicologias que pregam um apego demasiado ao subjetivismo ou ao objetivismo (Maheirie, 1994). Schneider (2008) afirma que a abordagem sartriana questiona perspectivas subjetivistas (como se houvesse um mundo interno do sujeito) e concepções mecanicistas (ênfase do ambiente sobre o sujeito), trazendo a dialética para compor a psicologia, possibilitando um olhar integrado entre o contexto e o sujeito. Essas perspectivas subjetivistas/mecanicistas têm sido alvo de crítica de diversos autores da psicologia social, tal como Moscovici e Marková (2006) na obra The making of modern social psychology, ainda sem tradução para o português.

Para além da contribuição de Sartre para a compreensão do sujeito, sua abordagem é consonante com seu caráter de intelectual engajado, possibilitando a transformação de contextos sociais por compreender o sujeito não apenas de forma singular, mas como parte de uma coletividade que o transforma e é transformada por ele (Sartre, 1987). Moura (2012) ainda

1 O conteúdo desse ensaio relaciona-se à dissertação de mestrado intitulada Projeto Exitencial, Internação Compulsória e Uso de Crack, de autoria de Cezar Augusto Vieira Junior, orientada por Adriane Roso e co-orientada por Hector Omar Ardans-Bonifacino. Integra o projeto guarda-chuva PROCUIDADO - O Cuidado que Nós Desejamos: Uso de Crack e Representações em Saúde. Experiências de Internação Compulsória. 
aponta a importância desse olhar abrangente, visto que a unilateralidade de pensamento pode colocar em risco inúmeras possibilidades de ser do sujeito. Sob esses aspectos, podemos dizer que o pensamento do filósofo se aproxima da psicologia social crítica, quando a constituição do sujeito é compreendida sempre a partir da relação sujeito-objeto-sociedade (mundo) (Guareschi \& Roso, 2014).

Nesse sentido, o objetivo de nosso estudo é elucidar como se dá o processo de construção do sujeito a partir da abordagem existencialista de Jean-Paul Sartre. Desenvolvemos este ensaio dividindo-o em três partes, sendo que, na primeira delas, abordamos aspectos mais básicos do pensamento sartriano. Em seguida, delineamos temas fundamentais de sua filosofia, tais como a liberdade, o campo dos possíveis e a má-fé. Na terceira parte concentramos a discussão sobre as relações e os processos que resultam, então, na concepção de sujeito. Na parte final, buscamos salientar algumas contribuições de Sartre ao campo da psicologia social.

\section{A Consciência e os Três Aspectos do Ser}

Antes de tudo, faz-se necessário um apontamento acerca da abordagem sartriana sobre a consciência. Sartre (2014) parte da abordagem fenomenológica husserliana, concordando que toda consciência é consciência de alguma coisa. Assim, ela não pode ser tomada em si mesma, pois é puramente relação e só existe na medida em que se realiza.

Maheirie (1994) auxilia a compreender os tipos de consciência propostos por Sartre dividindo-os em dois níveis, sendo eles: a consciência pré-reflexiva (irrefletida) e a consciência reflexiva. A consciência pré-reflexiva trata-se de uma consciência espontânea, que é posicional do objeto, mas não posicional de si, nem do sujeito. Isso quer dizer que ela é consciência do objeto visado (por exemplo, uma garrafa ou uma caneta), mas não é consciência de si mesma, ou seja, "a consciência não é para si mesma seu objeto" (Sartre, 2013a, p. 23). Por sua vez, a consciência reflexiva terá como seu objeto uma consciência, pois emitirá juízos sobre esta consciência refletida (Sartre, 2014). Nesse nível, a consciência é posicional de si (pois visa uma consciência) e também posicional do sujeito, presente na reflexão.

Ainda, observamos que não há um interior da consciência, pois ela é pura relação com as coisas. A consciência pode ser considerada um vazio, sem substância, e não pode ser tida como um objeto, completo e fechado em si mesmo, ou seja, a consciência não pode ser em-si. Na verdade, a consciência caracteriza-se justamente por ser sempre em relação a alguma coisa, constituindo-se como distância de si mesma, ou seja, a consciência é caracterizada como para-si. Schneider (2011, p. 87) explica que, com essa expressão, pretende-se "dar a noção de movimento, de relação a..., que caracteriza a consciência, diferente do ser em-si, que é opaco, fechado em si mesmo".

\section{Em-si, Para-si, Ser-para-outro}

Adentrando a discussão acerca da construção do sujeito sartriano, faz-se necessária uma diferenciação de três aspectos do ser apresentados por Sartre (2014): o ser-em-si, o ser-para-si e o ser-para-outro. O primeiro diz respeito ao ser dos objetos, é plenitude, escapando da temporalidade e esgotando-se em si mesmo. Assim, não estabelece relações e nega qualquer trânsito, ou um vir-a-ser, pois o ser-em-si jamais será possível ou impossível, ele simplesmente é o que é (Sartre, 2014).

Em contraponto ao ser-em-si está o ser-para-si. Ao contrário do em-si, que simplesmente é, o para-si busca a si mesmo. É a consciência que se lança no mundo através da intencionalidade, sempre em busca do ser e da completude do em-si. Porém, não há uma consciência senão em relação a um objeto, ou seja, a consciência não possui conteúdo, não é em-si, sendo que o si visado pela consciência está fora dela mesma, no mundo. O para-si, então, caracterizado pela falta, esvaziado de conteúdo próprio, transcende a si mesmo e vai ao encontro daquilo que deseja e lhe falta, que é sua fundamentação. O para-si é "o ser da consciência como sua condição de possibilidade" (Sartre, 2014, p. 121).

Dividindo-se o termo para-si, tem-se que o para indica a sua transcendência, é o movimento de saída em direção ao faltante, o em-si. É a busca pela completude, pelo preenchimento do nada. Por outro lado, o si é aquilo que está sendo transcendido, é o que se busca ser, porém, será constantemente falta. Nunca se dará de forma plena, "será sempre uma incompletude originária e uma tentativa de identificação e plenitude que se dá a cada instante e nunca se realizará completamente" (Santos, 2011, p. 57). Nas palavras de Sartre (2014, p. 147, grifo do autor): "É falta de... para ..., tal como o disco desfalcado da lua é falta do que necessitaria para se completar e transformar-se em lua cheia".

Para designar a ideia de construção contínua, como um vir-a-ser, Sartre (2014) propõe que a constituição do sujeito se dá como um projeto. A palavra projeto nos dá a ideia de algo que está inacabado, em andamento, e é exatamente esse o significado que o pensador francês busca ao utilizar esse termo. Anteriormente a esse projeto não existe nada. Com o início da existência, inicia-se também o projeto, que é continuamente um vir a ser, sempre inacabado (pois é para-si) e sempre constituindo o sujeito a partir de sua vivência. 
Se o ser-em-si diz respeito ao ser dos objetos, que é fechado e enrijecido em si mesmo, e o ser-para-si trata do ser da consciência, que é um processo contínuo de construção e abertura às possibilidades, temos aí dois vértices do triângulo que podemos considerar para delinear os principais aspectos do ser de que trata Sartre. O terceiro vértice desse triângulo constitui-se como o principal fundamento das relações que o sujeito vai estabelecer: o ser-para-outro.

Esse aspecto manifesta-se através do olhar do outro. Trindade (2013, p. 163) complementa esse pensamento expondo que "da mesma maneira que posso olhar o outro e defini-lo através de minha subjetividade, sei que o outro pode olhar-me e definir-me através de sua subjetividade". Assim, o outro será sempre um mediador entre mim e mim mesmo (Sartre, 2014). A partir da aparição do outro, formula-se sobre si um juízo tal qual formularia sobre um objeto, pois sob a ótica do outro, se é percebido como ser-em-si.

Experienciar a si mesmo dessa forma, como um objeto percebido pelo outro, é similar a deixar de ser transcendente, portador de um ponto de vista no mundo, e se tornasse apenas um objeto no mundo, visto pelo ponto de vista do outro. Assim, experienciar-se como objeto é experienciar ao outro como sujeito. Porém, ao mesmo tempo em que essa objetivação repele, também é atraente, pois concede ao para-si algo que ele tanto busca: a forma estável do em-si. Por outro lado, apesar de buscar essa estabilidade, o para-si não tem o desejo de perder sua fluidez e liberdade, ou seja, ele busca alcançar uma síntese perfeita, que Sartre (2014) chama de em-si-para-si. Apesar desse movimento do para-si, o projeto de alcançar tal perfeição sempre fracassa, pois essa objetivação é dada pelo olhar do outro, ou seja, vem de fora. Assim, o para-si acaba tendo enrijecida sua liberdade, pelo olhar e qualificação do outro. Gonçalves (2013) comenta que é a partir desse conflito entre a nossa liberdade e a liberdade do outro que surge a relação com o outro, tendo em vista que o outro é indispensável à nossa existência.

Sartre (2006) também aborda a relação com o outro através de sua obra literária $A$ Náusea. Aqui, uma reflexão do personagem Roquentin: "Talvez seja impossível compreender o próprio rosto. Ou talvez seja porque sou um homem sozinho? As pessoas que vivem em sociedade aprenderam a se ver nos espelhos tal como aparecem aos seus amigos" (Sartre, 2006, p. 31).

Assim, é também através do olhar do outro que nos constituímos. Apesar de seu aspecto objetivante, buscamos esse olhar para conhecer a nós mesmos. Vivemos um constante enfrentamento entre consciências no mundo, cada qual buscando exercer sua liberdade. Quando nossas expectativas estão de acordo com o olhar do outro, há uma trégua nesse conflito, caso contrário, o outro será um espelho crítico que aponta nossos vícios (Oliveira, 2008).

\section{Liberdade, Campo dos Possíveis e Má-fé}

A discussão acerca dos aspectos do ser nos leva ao principal fundamento do sujeito sartriano: a liberdade. Não sendo naturalmente determinado, o sujeito é livre para construir-se a partir de suas escolhas diante das possibilidades que o meio lhe dispõe. Nesse sentido, é importante destacar que o ser livre de que trata o existencialismo não significa obter o que se quer, e sim determinar-se a querer. O êxito não tem importância alguma para o conceito existencialista de liberdade. Assim,

(...) o conceito empírico e popular de "liberdade", produto de circunstâncias históricas, políticas e morais, equivale à "faculdade de obter os fins escolhidos". O conceito técnico e filosófico de liberdade, o único que consideramos aqui, significa somente: autonomia de escolha. (Sartre, 2014, p. 595)

Ressaltamos que a liberdade está diretamente relacionada com o movimento que o ser humano realiza no sentido de sua construção enquanto sujeito e totalização de seu projeto existencial. Em consonância, Schneider (2011, p. 168) afirma que "ser é escolher-se e essa escolha se dá como ação no mundo. Portanto, ser é agir - a liberdade é nossa ação sobre o mundo".

Compreendemos que a existência precede a essência (Sartre, 2013b), pois primeiro somos "lançados" no mundo, e, através das nossas vivências, das relações que estabelecemos, vamos construindo nosso ser. A essência a que se refere o pensador francês não está dada a priori, sendo construída através da existência. Tampouco será concluída em algum momento, pois é um processo, uma construção constante e transcendente que aponta para quem é o sujeito. Define-o até certo ponto, pois resguarda sua abertura sem enrijecê-lo em uma identidade. Por isso seria mais compreensível se déssemos essa mesma abertura ao termo utilizado e, ao invés do substantivo "essência", utilizássemos o verbo substantivado "o essencializar", que ainda assim vai dizer respeito a uma essência vindoura, mas aponta para o processo que levará até ela, e não para ela mesma.

É possível compreender, então, que a liberdade a que se refere nossa abordagem não diz respeito à gratuidade do acaso, como se a construção do sujeito escapasse a quaisquer designações do meio no qual ele se insere. A liberdade existe a partir de uma estrutura de escolhas em uma dada situação, a qual compreende as condições impostas pelo meio em que vivemos, pelas significações que damos às vivências de nosso passado e pelas relações que estabelecemos com os outros. 
A liberdade de escolha consiste na principal característica da condição humana, pois é precisamente através dela que temos a possibilidade de nos fazermos diferentes daquilo que foi feito de nós (Sartre, 1987). Mesmo que estejamos inseridos em um determinado contexto, não somos simplesmente condicionados por ele, nem somos unicamente um produto enrijecido do nosso passado ou das condições objetivas que nos rodeiam, pois o movimento é inerente à condição humana, seja no sentido de negar e superar as condições dadas, seja em acomodar-se a elas (Sartre, 2013b).

Consideramos, assim, a liberdade em situação, pois ela existe dentro do campo dos possíveis, que é construído historicamente. Porém, não podemos considerar esse campo como definido independentemente da ação humana no mundo. Para compreendermos essa construção histórica, precisamos entender o encadeamento de gerações, que demonstra como as objetivações resultantes das gerações passadas são subjetivadas pelas gerações seguintes. Nesse sentido, Marx e Engels defendem que:

A história nada mais é do que o suceder-se de gerações distintas, em que cada uma delas explora os materiais, os capitais e as forças de produção a ela transmitidas pelas gerações anteriores; portanto, por um lado ela continua a atividade anterior sob condições totalmente alteradas e, por outro, modifica com uma atividade completamente diferente as antigas condições. (Marx \& Engels, 2007, p. 40)

Essa proposição evidencia como acontece a construção de um dado contexto histórico e social que será o ponto de inserção do indivíduo no mundo. As condições que neste momento são dadas, eram ainda apenas possibilidades para uma geração anterior à nossa. $\mathrm{O}$ processo constitutivo desse contexto poderia ter seguido por outro caminho, através de outras escolhas, a partir do livre engajamento das pessoas daquela época, ou seja, o contexto a partir do qual o sujeito é construído também foi construído por outros sujeitos antes dele, sendo reconstruído através de sua práxis, e da de todos os outros sujeitos. Assim, concordamos com o pensamento de Marx e Engels (2007, p. 43), que propõem que "as circunstâncias fazem os homens (sic), assim como os homens (sic) fazem as circunstâncias".

Em consonância com essa ideia, Ricouer (1997, p.189, grifo do autor) também aborda o encadeamento de gerações como abertura para possibilidades: "essa combinação entre influências recebidas e influências exercidas explica o que faz a especificidade do conceito de 'sequência' de gerações. É um 'encadeamento' oriundo do cruzamento entre a transmissão da bagagem e a abertura de novas possibilidades".

Com a compreensão desse encadeamento e de seu resultado, contemplamos a ideia do campo dos possíveis, proposta por Sartre. Segundo o existencialista, o campo de possibilidades do sujeito está inserido dentro de suas condições materiais de existência e está estreitamente ligado à sua realidade social e histórica (Sartre, 1987). Este campo diz respeito às diversas possibilidades no movimento de subjetivação e objetivação da realidade do meio circundante, ou melhor, referese ao movimento de apropriação, interiorização e compreensão do meio em que o sujeito está inserido, e à consequente objetivação através da práxis, como uma devolução ao mundo daquilo que foi anteriormente apropriado. Contemplando essa discussão, Sartre (1987, p. 153) ainda afirma que: "é superando o dado em direção ao campo dos possíveis e realizando uma possibilidade entre todas que o indivíduo se objetiva e contribui para fazer história".

A partir, então, do campo dos possíveis, e de posse da liberdade em situação, o sujeito "escolhe-se" e vai sendo construído através de seu livre engajamento em sua vida. Porém, existe a possibilidade de que a pessoa incorra em algo que Sartre (2014) chama de má-fé, negando essa liberdade, como se já estivesse previamente determinada.

Na perspectiva existencialista, a má-fé só é possível devido à liberdade. Isso significa dizer que, pelo fato do ser humano constituir-se através de sua liberdade de escolha, cabe a ele mesmo a responsabilidade pelo que ele faz daquilo que foi feito dele (Sartre, 1987). Porém, a angústia resultante dessa responsabilidade pode tornar-se um fardo pesado demais, tendo em vista as possibilidades barradas no cotidiano ou mesmo a dificuldade em compartilhar essa angústia. Portanto, a má-fé é um estado espontâneo que possibilita escapar da angústia, negando a liberdade.

A má-fé pode ser compreendida como o ato de assumirmos espontaneamente uma identidade rígida, a ponto de negarmos que exista uma possibilidade de ser algo diferente, ou seja, negar a própria liberdade de escolha. Também pode ser considerada uma tentativa de fugirmos de nossa condição de liberdade, pois nos associamos a alguma imagem que criamos de nós mesmos ou algum papel social que desempenhamos, tentando retirar a liberdade (e a responsabilidade) de nossa ação, com o objetivo de aliviar nosso sentimento de angústia (Sartre, 2014).

A má-fé nos possibilita um sentimento de segurança, pois, já que nos encerramos nessa identidade, como se fôssemos apenas isso, não precisamos nos haver com a angústia proveniente da liberdade e a consequente responsabilidade de decidirmos sobre nosso projeto existencial. Ela concede a rigidez do ser-em-si, negando nossa transcendência. Porém não somos unicamente essa identidade assumida, pois somos para-si. Evidentemente ela também nos constitui, mas é apenas um aspecto de uma totalidade, dos demais papéis que assumimos (ignorados, nesse caso). 


\section{A Construção do Sujeito}

Após esta breve exposição de alguns conceitos importantes abordados por Sartre na proposição de sua abordagem existencialista, cabe agora discorrer acerca da construção do sujeito, e quais os fatores que têm influência sobre esse processo. Entendemos que o ser humano está inserido em um processo de relações, e a condição para que isso ocorra é o fato dele ser corpo/consciência. É através do corpo que temos nosso primeiro contato com o mundo, e é através da consciência que estabelecemos as relações com o mundo (Schneider, 2011). O ser humano, como sujeito, é social por condição e não se essencializa, não constitui seu ser sem a mediação do outro. Nesse sentido, abordaremos agora alguns aspectos importantes das relações estabelecidas nesse processo de construção do sujeito.

\section{Relação Com os Grupos Sociais}

Nas palavras de Sartre (1987, p. 146, grifo do autor):

Produto de seu produto, modelado pelo seu trabalho e pelas condições sociais da produção, o homem (sic) existe ao mesmo tempo no meio de seus produtos e fornece a substância dos "coletivos" que o corroem; a cada nível da vida, um curto-circuito se estabelece, uma experiência horizontal que contribui para modificá-lo sobre a base de suas condições materiais de partida: a criança não vive somente sua família, ela vive também - em parte através dela, em parte sozinha - a paisagem coletiva que a circunda.

Isso significa dizer que o ser humano realiza uma apropriação particular da realidade coletiva que o cerca, a qual ele mesmo contribui para construir. Ele é resultante desse processo de interiorização da exterioridade coletiva e da exteriorização de sua apropriação particular. O sujeito objetiva-se na história que produz, também se perdendo nela, pois ele sozinho não é o único produtor da história, que é construída coletivamente.

Assim, Sartre (1987) expõe que o existencialismo tem como objeto o ser humano singular, mas inserido no campo social. Nesse sentido, as relações entre as pessoas não acontecem simplesmente ao acaso, na verdade, são o resultado de diversas designações, sejam sociais, sejam culturais, sempre através das mediações exercidas pelo outro e pelo mundo.

É através dessas mediações vivenciadas que a pessoa poderá transformar seu contexto social e apropriar-se de suas significações. O ser humano é sempre em relação, e suas vivências no mundo serão sempre mediadas pelo outro. De certa forma, somos meio, uns para os outros, para realizarmos nosso projeto existencial.

Esse processo de socialização é definido por Schneider (2011) como um tecimento afetivo com as pessoas significativas, as quais auxiliam na definição do ser (valores, crenças, concepções de mundo), por isso é importante salientar que o outro é mediação para mim, da mesma forma que sou mediação para o outro. As relações humanas, de forma geral, são mediadoras da materialidade e, ao mesmo tempo, mediatas por ela. Temos um campo de reciprocidade, que é uma relação humana fundamental, e é a condição de possibilidade para qualquer agrupamento humano (Bettoni \& Andrade, 2002).

A pessoas da família, ou as pessoas cuidadoras durante a infância, podem ser consideradas o principal grupo social no início da construção do sujeito, devido ao papel de mediação inicial que desempenham entre o indivíduo e a sociedade (Schneider, 2011). Esse grupo inicial apresenta-se como uma expressão da comunidade da qual o sujeito é proveniente (Sartre, 1987), dispondo-lhe as primeiras possibilidades de sua ação sobre o mundo. A ação apresentada de interiorização da exterioridade resulta no processo de construção do sujeito, e, pelo fato da família apresentar-se como o primeiro grupo onde o sujeito está inserido, é ela que realiza esse papel fundamental através da mediação indivíduo-sociedade.

A criança sempre nasce em um determinado contexto social, ou seja, em um determinado local, com sua cultura e valores específicos, em certa época e em determinada classe social, a qual apresenta suas condições materiais e ideológicas específicas. A inscrição nesse meio social é a primeira condição para a construção do sujeito (Schneider, 2011). Nas palavras de Martins, Tassigny, Carvalho e Santos (2013, p. 606, grifo do autor):

Já se nasce afetado por um discurso estabelecido, por uma moral de referência partilhada sobre o que é bom e correto, de acordo com o tempo (época) em que se está inserido. Isso é o que posiciona o sujeito afetivamente em detrimento do que está posto. Seus sentimentos serão, por assim dizer, temperados ao sabor das possibilidades que a sua relação pôde experimentar.

As relações sociais e materiais serão vivenciadas pela criança, desde o início de sua vida, através da mediação da família. Porém, em um primeiro momento, a criança não totaliza essas vivências no sentido de constituir-se como sujeito, pois não tem ainda desenvolvida a capacidade reflexiva, a qual permite ao ser humano distanciar-se dos objetos ou outras pessoas, diferenciá-los e diferenciar-se deles (Schneider \& Castro, 1994). A criança não nasce com essa capacidade reflexiva, 
mas aprenderá a refletir conforme for obtendo conhecimento sobre o mundo (a partir da mediação), começando assim a constituir-se. Maheirie (1994) argumenta que a época exata em que a criança começa a posicionar-se reflexivamente sobre sua experiência pode depender do contexto social e cultural no qual está inserida, além de sua singularidade, o que dificulta precisar o momento de tal etapa. Essa reflexão vai sendo constituída na medida em que o sujeito mesmo é construído, a partir da síntese das relações vividas entre corpo/consciência e o mundo.

O contexto e estrutura social nos quais o indivíduo encontra-se inserido fornecem um horizonte em que ele encontrará as ferramentas para construir sua singularidade, apropriando-se das práticas sociais, das ideologias e dos valores historicamente construídos. A mediação exercida pelas pessoas próximas à criança, relacionando os valores sociais e culturais às necessidades apresentas por ela, vai aos poucos realizando o processo de socialização. Schneider (2011) utiliza um termo que faz parte do arcabouço teórico do psicodrama, placenta social, para definir este espaço existencial e sociológico vivenciado pela criança, em que ela é "alimentada" com conhecimentos, valores, crenças e afetividade, os quais possibilitarão sua formação como sujeito humano. Neste caso, as pessoas mais próximas vão desenvolvendo um projeto para a criança, através de suas expectativas, por exemplo, como ela deve se comportar, do que deve gostar e que papel deve desempenhar no grupo familiar. Apesar da criança não dispor de uma capacidade reflexiva, as pessoas que a cercam acabam lhe conferindo uma identidade (Schneider \& Castro, 1994).

Sartre (1987, p. 156, grifo do autor) define essa etapa da seguinte forma:

Esta (a infância), que foi ao mesmo tempo uma apreensão obscura de nossa classe, de nosso condicionamento social, através do grupo familiar e uma superação cega, um esforço canhestro para nos arrancar daí, acaba por inscrever-se em nós sob a forma de caráter. É neste nível que se encontram os gestos aprendidos (...) e os papéis contraditórios que nos comprimem e nos dilaceram.

A configuração familiar a que pertence é interiorizada por ela como atitudes e exteriorizada por práticas, através das quais ela se faz aquilo que fizeram dela. As atitudes, ações e emoções encontradas na infância se originam a partir do que foi interiorizado pela criança, em um movimento de totalização e destotalização, de acordo com suas relações fundamentais.

Nesse sentido, irá se construir o projeto de ser da criança, suas particularidades, sempre na forma de totalização em curso. Isso caracteriza o início da construção do sujeito, que pode ser definida como sendo "a superação e a conservação (assunção e negação íntima), no seio de um projeto totalizador, daquilo que o mundo fez - e continua a fazer - dele" (Sartre, 2013c, p. 657).

Neste momento, a criança estabelece apenas relações espontâneas com o ambiente que a cerca, e, mesmo que venha a apresentar atitudes de contestação ou insubordinação, ela ainda não vivencia o seu ser. Assim, são as pessoas próximas que afirmam uma verdade sobre o ser da criança, e ela se apropria disso como se fosse sua única possibilidade de mundo, vivenciando seu ser no sentido de um dever ser (Schneider \& Castro, 1994).

Aos poucos a criança vai inserindo-se em diferentes grupos sociais, tendo acesso a mais informações, outros valores e regras morais, ampliando seu horizonte de ser. Ela irá estabelecer novas relações sociais e terá a experiência de novas mediações, relativizando o processo de mediação estabelecido até então pela família. Essa nova situação traz a possibilidade de que a criança estabeleça reflexões mais elaboradas sobre si mesma e sobre os outros com quem se relaciona. Esse momento configura uma espécie de nascimento existencial, que acontece a partir do momento em que a criança rompe a placenta social, superando o dever ser em direção ao poder ser. Tomando para si, então, seu projeto existencial. O sujeito será, então, o resultado desse processo de construção histórico e social, o qual se desenvolve através da dialética entre objetividade e subjetividade (Schneider, 2011).

\section{A Formação do Ego}

Após explorarmos como se dá o processo de socialização e constituição do sujeito na mediação com os grupos sociais, cabe agora um olhar mais apurado sobre como ocorre, no indivíduo, o processo de formação do ego. Aqui é necessário retomar o que já foi estudado a respeito da consciência.

Lembremos da divisão entre os níveis de consciência propostos por Sartre (2013a): a consciência pré-reflexiva (irrefletida, ou espontânea) e a consciência reflexiva. O primeiro tipo é entendido como uma consciência de primeiro grau, pois estabelece espontaneamente sua relação com o objeto, sem a necessidade de uma consciência anterior que a designe. Por sua vez, a consciência reflexiva é entendida como uma consciência de segundo grau, pois primeiro existe uma consciência do objeto e depois uma reflexão sobre ele. É uma consciência que se dirige sobre outra consciência, tomando-a como objeto (Sartre, 2013a).

O ego aparece a partir da consciência de segundo grau, a partir de sua posição na reflexão. Porém, ainda que não apareça 
na consciência de primeiro grau, as vivências espontâneas também afetam o sujeito, participando de sua construção. Em consonância, Spohr (2011, p. 912) afirma que "é neste plano que se vive concretamente quem se é, onde se é psicofisicamente atingido pelas experiências".

Buscando explorar os aspectos do ego, Sartre (2013a) utiliza-se dos termos franceses Je e Moi. O aspecto passivo do ego, Sartre chama de $M o i$, que representa as vivências espontâneas que são apropriadas pela consciência e servirão de objeto para uma consciência de segundo grau. A face ativa é designada pelo existencialista como Je, que configura o movimento efetivo do ego na apreensão e reflexão acerca das vivências. Je é o aspecto ativo da personalidade, e Moi, a totalização psicológica da personalidade (Sartre, 2013a).

Mas é importante ressaltar que Je e Moi são dois aspectos de uma realidade, ambos constitutivos do ego, sendo a diferenciação entre eles apenas uma questão funcional (Sartre, 2013a). Assim, podemos compreender que:

O Ego, sob a dupla forma gramatical do $\mathrm{Eu}(\mathrm{Je})$ e do Mim (Moi), representa nossa pessoa, enquanto unidade psíquica transcendente. (...) É enquanto Ego que somos sujeitos de fato e de direito, ativos e passivos, agentes voluntários, possíveis objetos de juízo de valor ou responsabilidade (Sartre, 2014, p. 221, grifos do autor).

Consciência e ego não podem ser tomados como sinônimos, nem equiparados. Além disso, o ego não é anterior à consciência, como se esta partisse dele e ele a conduzisse. É a consciência, na verdade, que é anterior ao ego, pois é a partir das relações estabelecidas através dela que ele é constituído (Sartre, 2013a).

Nesse sentido, Sartre (2014) propõe que o ego se constitui através de estados, qualidades e ações. Na vivência de situações que proporcionem emoções, somos afetados psicofisicamente de forma espontânea (consciência de primeiro grau, portanto, não reflexiva). Essas afetações são aos poucos apropriadas pelo sujeito à medida que vão ocorrendo e se repetindo, configurando uma experiência vivenciada e reconhecida por ele. Essas afetações, que se tornam experiência e comprometem o sujeito em seu futuro, constituem um estado, que, de acordo com Sartre (2013a), pode ser compreendido como um intermediário entre o corpo e a vivência.

Os estados não são emoções momentâneas, mas se consolidam a partir de experimentações que acontecem espontaneamente, possuindo um caráter de permanência. Dessa forma, eles transcendem situações especificas e constituem o projeto de ser, definindo como o sujeito é afetado em determinadas situações, na relação com os outros e com o mundo (Schneider, 2011).

As ações, por sua vez, são um aspecto constituinte do ego que têm relação direta com a práxis que o sujeito desenvolve no mundo. Nosso ser é definido a partir das ações que realizamos, pois o ser humano é aquilo que ele faz (Sartre, 2013b). Conforme já foi explorado, não nascemos previamente determinados, vamos nos constituindo à medida que agimos no mundo. É através de nossa ação que somos comprometidos e reconhecidos como seguindo em determinada direção. Somos uma pessoa ou outra conforme realizamos nossa práxis. Assim, é possível compreender que "nada é considerado inato ou inerente ao sujeito, não há necessidade humana posta fora ou além de sua própria produção: tudo que é humano é produto da ação humana" (Diogo \& Maheirie, 2007, p. 140).

Cabe salientar que, da mesma forma como acontece com os estados, a forma como o sujeito realiza suas ações é construída ao longo de sua história. Nesse caso, a compreensão do contexto material, antropológico e sociológico em que se encontra o indivíduo é de fundamental importância.

Finalmente, as qualidades podem ser entendidas como a unidade dos estados (Schneider, 2011), e uma intermediária entre eles e as ações (Sartre, 2013a). Os estados constituem as qualidades a partir do momento em que o sujeito vivencia uma determinada emoção com frequência, e quando reage a certas situações sempre da mesma forma. Nas palavras de Sartre (2013a, p. 45):

Quando experimentamos diversas vezes ódio em relação a diferentes pessoas, ressentimentos tenazes ou longa cólera, nós unificamos essas manifestações intencionando uma disposição psíquica de produzi-las. Essa disposição psíquica (eu sou muito rancoroso, sou capaz de odiar violentamente, sou colérico) é, naturalmente, algo mais, e uma coisa diferente do que um simples meio. É um objeto transcendente.

Assim, o ego é uma unificação constante dos estados, ações e qualidades do sujeito. Schneider (2011) compara essa totalização a uma sinfonia, na qual a melodia que se apresenta vai além das notas que a compõem, por isso o ego não pode ser considerado como existindo anteriormente à essa unificação, pois ele é resultado dela (Sartre, 2013a). Não há uma vida interior que antecede esses aspectos ou algo definido a priori e que conduz a consciência na totalização do sujeito. Diante disso, o pensador francês conclui: 
Afinal de contas tudo está fora, tudo, até nós mesmos: fora, no mundo, entre os outros. Não é sabe-se lá qual retraimento que nos descobriremos: é na estrada, na cidade, no meio da multidão, coisa entre as coisas, homem (sic) entre os homens (sic) (Sartre, 2005, p. 57).

\section{Um Método Sartriano como Contribuição para a Psicologia Social}

De posse da compreensão acerca do processo de construção do sujeito na perspectiva sartriana e dos principais pontos expostos pelo existencialista em seu pensamento, agora voltamos nosso olhar para algumas elaborações de Sartre que se apresentam como importantes contribuições do autor para a psicologia social. Maheirie e França (2007, p.28) são pioneiras em reconhecer que Sartre apresenta “contribuições metodológicas importantes para a Psicologia Social, desenhando-se uma possibilidade de compreender tanto as significações que alguém atribui ao mundo, quanto de apreender, no sujeito, as múltiplas relações que o constituem".

Ainda devemos salientar que, na quarta parte da obra O Ser e o Nada, Sartre (2014) apresenta a Psicanálise Existencial, uma proposta para a investigação da realidade humana, escrito que talvez mais se aproxime de uma psicologia social, embora, é importante destacar, Sartre nunca se distanciasse das questões sociais.

Seguindo o pressuposto de que o ser humano, por não apresentar uma natureza previamente determinada, é livre e, por isso, precisa construir-se a partir de suas escolhas, a abordagem psicológica existencialista tem como seu aspecto central as questões sobre as escolhas que o sujeito faz de si mesmo. Essas escolhas, por sua vez, vão se refletir em suas ações, em seus sentimentos, caracterizando a forma como ele significa suas vivências e as relações que estabelece, ou seja, evidenciando o seu projeto existencial. Essa abordagem possibilita condições para a compreensão objetiva do movimento do ser humano no mundo, uma forma de captar o seu ser, conforme indica Schneider (2011). Nas palavras de Sartre (2014, p. 702), “ é um método destinado a elucidar, com uma forma rigorosamente objetiva, a escolha subjetiva pela qual cada pessoa se faz pessoa, ou seja, faz-se anunciar a si mesma aquilo que ela é”.

O existencialismo dá inserção e ação ao ser humano no mundo. Isso nos remete a uma relação estreita com a psicologia social, particularmente uma psicologia social crítica, em que o conceito de relação pode ser considerado um de seus operadores teóricos mais importantes, como afirma Guareschi (2012). Neste sentido, esse autor ainda salienta que, "para haver relação não é necessário que haja duas coisas: basta apenas uma que contenha em si, em sua definição, a necessidade, a orientação intrínseca em direção a outro(s)" (Guareschi, 2012, p. 61).

Em Questão de Método, introdução à obra Crítica da Razão Dialética, Sartre (1987) aprofunda sua proposta metodológica trazendo para sua abordagem a concepção histórico-dialética na compreensão do projeto existencial, tomando o sujeito singular inserido no campo social. Assim, o método progressivo-regressivo busca compreender o universal a partir de uma situação singular; da mesma forma que volta sua atenção a este singular, sem destacá-lo do universal. Conforme Sartre (1987, p. 171), “determinará progressivamente a biografia, aprofundando a época, e a época, aprofundando a biografia”.

A abordagem psicológica existencialista se dá, então, em dois momentos: primeiro, apreendemos a universalidade onde estamos inseridos, ou seja, a materialidade, o meio social, a história concreta, os grupos dos quais fazemos parte. Tudo aquilo que nos passa e nos constitui. Todas as mediações que se apresentam para nós. Essa análise pode nos mostrar como fomos construídos através do tempo, como uma biografia externa a nós.

A seguir, fazemos o movimento contrário. Analisamos a singularidade diante da universalidade que nos foi apresentada. Dessa forma, buscamos desvelar as escolhas que efetuamos a partir do campo dos possíveis que vivenciamos, e a forma como essas escolhas se deram em nossa práxis, construindo o mundo que, por sua vez, voltará a nos construir. Nesse movimento, compreendemos como as relações mediadas, as experiências vivenciadas e as escolhas que fizemos (mesmo as alienadas), construíram o sujeito que somos e abriram as possibilidades para nossa realização enquanto projeto.

Sartre complementa esse pensamento concluindo que:

A volta à biografia mostra-nos os hiatos, as fissuras e os acidentes ao mesmo tempo que confirma a hipótese (do projeto original) revelando a curva da vida e sua continuidade. Definiremos o método existencialista como um método progressivoregressivo e analítico-sintético; é ao mesmo tempo um vaivém enriquecedor entre o objeto (que contém a época como significações hierarquizadas) e a época (que contém o objeto na sua totalização). (Sartre, 1987, p. 176)

O método proposto por Sartre possibilita a compreensão do sujeito por inteiro, isso quer dizer que não se refere a um olhar sobre um indivíduo isolado de sua historicidade e cultura. O sujeito é tomado no mundo, entre os outros, entre os objetos, sendo salientada a teia de relações que é aí construída, tal como propõe a Psicologia Social crítica que coloca a historicidade e a alteridade como elementos constituidores das biografias. 


\section{Considerações Finais}

Ao término deste ensaio, em que foram explorados aspectos importantes da abordagem existencialista de Jean-Paul Sartre, podemos finalmente compreender este sujeito histórico e dialético que foi delineado sob a perspectiva sartriana. Construído a partir das mais diversas relações que desenvolve ao longo de sua vida, esse sujeito vai apropriando-se da realidade que o cerca ao mesmo tempo que, através de sua práxis, colabora para a construção dessa realidade.

Podemos salientar aqui a relação entre liberdade e responsabilidade. Levando em conta o campo dos possíveis que nos é apresentado em determinada época, somos livres para fazermos nossas escolhas no sentido de construirmos constantemente nosso projeto existencial. Podemos dividir um pouco da angústia da responsabilidade que nos cabe através das relações que estabelecemos, na tentativa de "compartilhar" o peso da escolha. Porém, ainda assim, somos nós que decidimos fazer (ou não fazer), ir (ou não ir), parar (ou não parar).

O existencialismo nos devolve nossa vida, colocando em nossas mãos o futuro, de forma que cabe a nós mesmos a realização do nosso projeto. Ele extrai qualquer determinismo que acorrente nosso ser a uma estrutura dada e estabelecida a priori, tal como pressupõe uma psicologia que faz a crítica de si mesma "Você não é outra coisa senão sua vida", afirma Sartre (2013b, p. 43), pois somos um somatório das relações que estabelecemos, das escolhas que fazemos, das ações que realizamos.

O ser humano é um ser social, portanto nossas escolhas não acontecem isoladamente. Nossa liberdade é mediada pela do outro, da mesma forma que também nós fazemos essa mediação. É através da práxis coletiva que é construída a história, então, nossas ações individuais também compõem essa construção. Assim, se desejamos que o mundo seja de certa maneira, cabe a nós mesmos assumirmos a responsabilidade de agirmos no sentido de realizá-lo. O existencialista contempla essa questão ao afirmar que:

As coisas serão exatamente como o homem (sic) decidir que elas sejam. Agora, isso significa que devo abandonar-me ao quietismo? Não! Antes de tudo, devo engajar-me, e depois agir de acordo com a antiga fórmula "Não é preciso esperar para começar". (Sartre, 2013b, p. 41).

\section{Referências}

Bettoni, R. A., \& Andrade, M. J. N. (2002). A formação dos grupos sociais em Sartre. Revista Metavnoia, São João Del-Rei, (4), 67-75.

Diogo, M. F., \& Maheirie, K. (2007). Uma breve análise da constituição do sujeito pela ótica das teorias de Sartre e Vygotski. Aletheia, (25), 139-151.

Gonçalves, A. I. (2013). O encontro com o outro em Jean-Paul Sartre. Griot: Revista de Filosofia, 8(2), 55-71.

Guareschi, P. (2012). Psicologia social crítica como prática de libertação. Porto Alegre: EDIPUCRS.

Guareschi, P., \& Roso, A. (2014). Teoria das representações sociais: Sua história e seu potencial crítico e transformador. In E. M. Q. O. Chamon, P. A. Guareschi, \& P. H. F. Campos (Orgs.), Textos e debates em representação social (pp.17-40). Porto Alegre: ABRAPSO.

Maheirie, K. (1994). Agenor no mundo: Um estudo psicossocial da identidade. Florianópolis: Letras Contemporâneas.

Maheirie, K., \& França, K. B. (2007). Vygotski e Sartre: Aproximando concepções metodológicas na construção do saber psicológico. Psicologia \& Sociedade, 19(1), 23-29. https://dx.doi.org/10.1590/S0102-71822007000100004

Martins, J. C. O., Tassigny, M. M., Carvalho, D. F., \& Santos, A. M. (2013). Sobre ter e ser a partir das coisas: Reflexões sobre consumo, subjetividade e satisfação no tempo livre. Revista Mal-estar e Subjetividade, 13(3-4), 591-618.

Marx, K., \& Engels, F. (2007). A ideologia alemã. São Paulo: Boitempo Editorial. (Originalmente publicado em 1932)

Moscovici, S., \& Marková, I. (2006). The making of modern social psychology. The hidden story of how an international 
social science was created. Cambridge: Polity Press.

Moura, M. T. C. (2012). Um olhar sartriano para o especialismo "psi” contemporâneo. Estudos e pesquisas em psicologia, 12(3), 767-791.

Oliveira, C. M. C. (2008). A psicanálise existencial de Jean-Paul Sartre na peça “Entre Quatro Paredes”: O jogo de espelhos no encontro com o Outro. In Anais do I Simpósio de Psicologia Fenomenológico-Existencial (p. 19). Belo Horizonte, MG.

Ricouer, P. (1997). Tempo e narrativa. Campinas. SP: Papirus.

Santos, T. S. (2011). Intersubjetividade em Sartre: O para-si e o para-outro. Trilhas Filosóficas, 4(2), 49-60.

Sartre, J. P. (1987). Questão de método. In Coleção Os pensadores (3a ed., pp. 109-191). São Paulo: Nova Cultural. (Originalmente publicado em 1960)

Sartre, J. P. (2005). Situações I. São Paulo: Cosac Naify. (Originalmente publicado em 1947)

Sartre, J. P. (2006). A náusea. Rio de Janeiro: Nova Fronteira. (Originalmente publicado em 1938)

Sartre, J. P. (2013a). A transcendência do ego: Esboço de uma descrição fenomenológica. Petrópolis, RJ: Editora Vozes. (Originalmente publicado em 1936)

Sartre, J. P. (2013b). O existencialismo é um humanismo (3a ed.). Petrópolis, RJ: Vozes. (Originalmente publicado em 1946)

Sartre, J. P. (2013c). O idiota da família: Gustave Flaubert de 1821 a 1857, Vol. 1. Porto Alegre: L\&PM Editores. (Originalmente publicado em 1971)

Sartre, J. P. (2014). O ser e o nada: Ensaio de ontologia fenomenológica (23a ed.). Petrópolis, RJ: Editora Vozes. (Originalmente publicado em 1943)

Schneider, D. R. (2008). O método biográfico em Sartre: Contribuições do existencialismo para a psicologia. Estudos e pesquisas em psicologia, 8(2), 289-308.

Schneider, D. R. (2011). Sartre e a psicologia clínica. Florianópolis: Editora da UFSC.

Schneider, D. R., \& Castro, D. J. (1994). Contribuições da psicologia existencialista para a psicologia social crítica. Cadernos de Psicologia, Rio de Janeiro, 8(1), 139-149.

Spohr, B. (2011). A noção de psíquico na teoria do imaginário de Sartre. Psicologia USP, 22(4), 907-925.

Trindade, R. (2013). Sartre: A consciência de ser visto. Alabastro: Revista Eletrônica dos Alunos da Escola de Sociologia e Política de São Paulo, 2(1), 157-168. 


\section{Endereço para correspondência}

Cezar Augusto Vieira Junior

End.: Rua Tuiuti, 2210, ap 305, Centro. Santa Maria, RS. CEP 97050-420

E-mail: cezaugjr@gmail.com

Hector Omar Ardans-Bonifacino

End.: Av. Roraima, 1000, Prédio 74B, Sala 3211. Cidade Universitária. Bairro Camobi. Santa Maria, RS. CEP 97105-900

E-mail: omardans@gmail.com

Adriane Roso

End.: Av. Roraima, 1000, Prédio 74B, Sala 3210A. Cidade Universitária. Bairro Camobi. Santa Maria, RS. CEP 97105900

E-mail: psicosocial.ufsm@gmail.com 